\title{
NATURE
}

\section{Apollo Rides Again}

There are several things to be said about the flight of Apollo 10, and most of them are polite. First, Apollo 10 has demonstrated the technical virtuosity of NASA and its works. It is hard now to remember that it is merely two years since an unlucky fire cost the lives of three astronauts at Cape Kennedy. Then it seemed as if the dream of getting to the Moon before the end of the sixties would be broken. Now, as the numbers tick by towards eleven, the meticulous care with which the whole enterprise has been conducted becomes in. creasingly apparent. The Apollo programme seems to be bursting with a host of technological sagas. There is the tale of how it has been possible to save nine pounds in the weight of the system which will eventually be landed on the Moon by welding together the halves of a pair of fuel tanks, not bolting them. The intricate system of webbing supports that will hold the pilots in a more or less vertical position as their craft approaches the surface of the Moon is a masterpiece of forethought. It is true that the United States is hoping that there will flow from this accumulation of expcrtise a further refinement of the skill of technological management which has made it the inventive place it is already, and there must be some truth in that. But ihe more lasting achievement is the way in which the anticipation of technical problems has created a sense of mastery of machines. Flimsy landing modules have become extensions of the personality. The old cliché of the returning hero that it is the team which deserves the honours has become a truism. That is something to think about.

But what is the future of the Apollo programme? The way things are going, the immediate objective will be reached before the year is out. Even if the next shot in July should be unlucky, there will be time to try again before the year is out. Naturally enough, NASA is beginning to worry what will happen afterwards. This is why the agency went begging to Congress at the end of March for a supplement to its budget, and the modest reduction which the President asked for at the beginning of April is not a final proof that the wind will never blow the other way. The successes of the past few months could well melt the heart of Congress. There is at least a chance. In any case, it now looks very much as if NASA will be able to squeeze close on half a dozen flights to the Moon out of the funds already voted.

By 1971, work should begin on the Apollo Applications Programme, now largely linked with talk of the assembly of huge space stations in orbits about the Earth. It is understandable that NASA should be anxious about the continuity of its programme, and it would be a waste of the capital resources locked up in the Apollo Programme if there were not enough money to support the launching of four or five large rockets every year, usually with men riding in them. When the Moon has been reached, however, it will be best if NASA can settle down to the steady exploitation of the resources which will by then exist. There will be trouble enough with the nuclear rocket engine, while there is already a crying need for a more sober interaction between the money spent on scientific research and the legitimate needs of the scientific community. The moral is that Congress should be generous now even allowing the NASA budget to rise a little above the $\$ 3,500$ million estimated for the coming fiscal year. When the committee under the Vice-President comes to report in September, however, it will be time to reconsider the relationships between NASA and the Air Force (which could become an unnecessary rival) and the scientific community (which has become a poor relation).

There remains the issue of what the first journey to the Moon can be expected to accomplish. Now and not later is the time to ask this awkward question. It is only fair to everybody to acknowledge that a brief visit of two hours to the surface of the Moon and the recovery of 40 kilograms of material will not immediately put solar system physicists out of business. The best immediate outcome will be a decent analysis of representative material from the Moon, and there is a chance that this may have some useful implications for the composition of the primaeval matter of which the other members of the solar system are constructed. With luck, radioactive analysis of surface material may also provide some kind of yardstick for working out the history of meteorites from the signs of cosmic ray bombardment. The chances are much smaller that the first few visits to the Moon will provide an explanation of its history. Whether the craters are tectonic, the consequences of impact or a mixture of both will not be decided on the first trip. The mascons which have excited interest in the past few months will be even harder to account for without some form of survey on the Moon, but it is important that these are consistent with much earlier evidence that the Moon is not in isostatic equilibrium derived, for example, from the inequality of the moments of inertia which are indicated by observations of the libration of the Moon. The Moon is almost certainly a planet not sufficiently massive to have developed fully, which implies that such surprises as Apollo 11 will bring may not say much about the rest of the solar system. To believe otherwise is to expect too much of the three brave men who will set off for the Moon in July this year. 